\title{
Проблема накопления отходов в отраслях добывающей промышленности РФ 1
}

T.о. TAГАEВА, доктор экономических наук, Институт экономики и организации промышленного производства СО РАН, Новосибирский государственный университет. E-mail: tagaeva@ieie.nsc.ru

В.М. Гильмундинов, кандидат экономических наук, Институт экономики и организации промышленного производства СО РАН, Новосибирский государственный университет. E-mail: gilmundinov@mail.ru

Л.К. КАЗАНЦЕВА, кандидат исторических наук, Институт экономики и организации промышленного производства СО РАН, Новосибирск. E-mail: klk@ieie.nsc.ru

Аннотация. В статье рассматриваются проблемы образования и накопления отходов в добывающем секторе и сопряженных отраслях, занятых переработкой его продукции. Данные сферы деятельности являются основным источником формирования отходов производства в России. Авторами рассчитаны показатели прямой и полной отходоемкости в данных отраслях, позволяющие оценить нагрузку на окружающую природную среду. Проанализированы материалы Стратегии развития промышленности по обработке, утилизации и обезвреживанию отходов производства и потребления на период до 2030 года. В статье рассматриваются основные направления совершенствования институциональных механизмов российского экологического законодательства, необходимые для успешной реализации целей и задач, изложенных в данном документе.

Ключевые слова: образование и накопление производственных отходов; техногенные месторождения; показатели прямой и полной отходоемкости; Стратегия развития промышленности по обработке отходов

\section{Введение}

С принятием в 2014 г. федерального закона № 458-Ф3² в России началось реформирование системы обращения с отходами. С точки зрения экономистов-экологов реформы действительно были необходимы: в данной области антропогенного воздействия на окружающую среду сложилась крайне негативная ситуация, которую до сих пор не удалось преодолеть.

\footnotetext{
${ }^{1}$ Работа выполнена по плану НИР ИЭОПП СО РАН, проект ХІ.170.1.1. «Инновационные и экологические аспекты структурной трансформации российской экономики в условиях новой геополитической реальности», № AАAА-А17-117022250127-8.

${ }^{2}$ См. федеральный закон № 458 ФЗ от 29.12.2014 «О внесении изменений в ФЗ № 89-Ф3 от 24.06.98 “Об отходах производства и потребления” и отдельные законодательные акты РФ».
} 
Растет как ежегодный объем образования отходов производства и потребления (в 2017 г. - более чем в два раза по сравнению с 2005 г. (рис. 1)), так и объем накопленных отходов, оценка которых весьма условна: от 30 до 100 млрд т. Такой разброс цифр при оценке объясняется рядом объективных и субъективных причин и сложностей. С одной стороны, ранее накопленные отходы подвергаются процессам разложения, выветривания, вымывания и зарастания растительностью, с другой, неконтролируемо организуются несанкционированные свалки, и широко развит теневой бизнес в этой сфере.

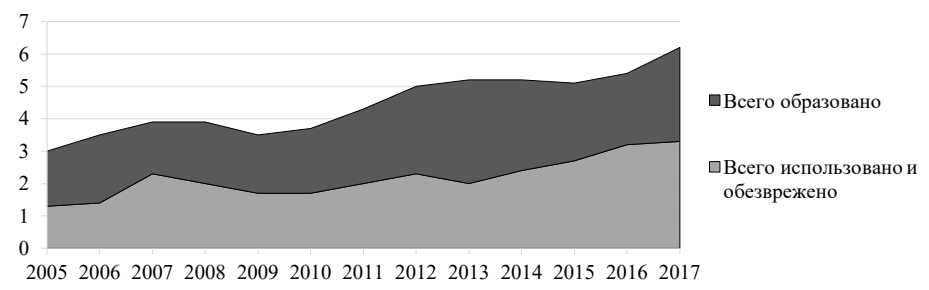

Источник рис. 1, 2: составлено по данным Росстата.

Puc. 1. Динамика образования, использования и обезвреживания отходов производства и потребления в 2005-2017 гг., млрд т

Степень использования и обезвреживания отходов в 2016 г. составила $59,3 \%$, в 2017 г. - 53,2\%. В развитых европейских странах доля отходов, вовлеченных в повторное производство, составляет 80-87\%, что значительно превышает аналогичный показатель в России ${ }^{3}$.

Наибольший вклад в образование отходов в РФ вносит горнодобывающая промышленность, а именно - добыча угля и торфа, причем доля отрасли в общем объеме промышленных отходов, по данным Росстата, существенно увеличилась за последнее десятилетие: с 49\% в 2005 г. до 62,3\% в 2017 г. (рис. 2). Большое количество отходов (24\% общего объема) возникает при извлечении металлических руд. На долю добычи прочих полезных ископаемых приходится около 6-10\%.

\footnotetext{
${ }^{3}$ Распоряжение Правительства от 25.01.2018 г. № 84-р об утверждении Стратегии развития промышленности по обработке, утилизации и обезвреживанию отходов производства и потребления на период до 2030 г. С. 6. URL: http://static.government.ru/ media/files/y8PMkQGZLfbY7jhn6QMruaKoferAowzJ.pdf (дата обращения: 15.03.2019).
} 


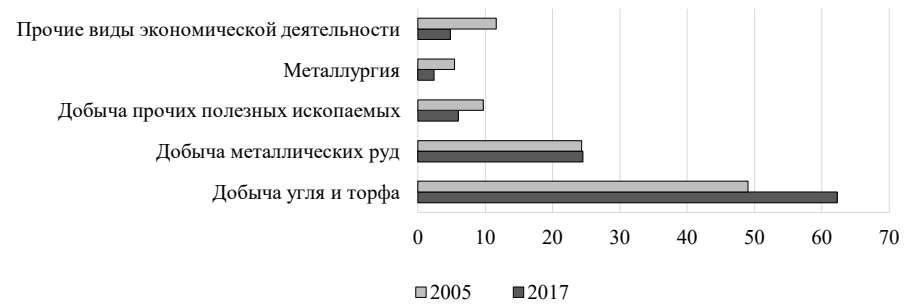

Puc. 2. Вклады отраслей в образование отходов в 2005 г., 2017 г., \%

Примечательно, что при добыче сырой нефти и природного газа отходов почти не образуется (менее $1 \%$ от суммарного объема). Однако, с нашей точки зрения, из-за особенностей статистического учета, экологический вред от данного вида деятельности, в том числе - в области образования отходов, сильно недооценен. Сегодня буровые растворы классифицируются как сточные воды, хотя по степени воздействия на окружающую среду их логичнее считать жидкими отходами. Вред наносится как от проникновения нефтепродуктов в почву и грунтовые воды, так и в виде испарений в атмосферу. Например, с одного только Туймазинского нефтегазового месторождения в атмосферу попадает до 123 т нефтепродуктов ежегодно [Ладыгин и др., 2018].

Существен вклад в образование отходов добычи неэнергетических ископаемых (камня, гравия, песка, глины, фосфатов, калийных солей и др.), а также отраслей, перерабатывающих продукцию добывающего сектора. Например, на долю металлургии приходится 2-5\% общего объема отходов.

В макрорегиональном разрезе первое место в стране по количеству отходов занимает Сибирский федеральный округ (4417,6 млн т, или 71\% от их общего количества в 2017 г.). Главным образом - «благодаря» вкладу Кемеровской области, основного угледобывающего региона РФ. Образование отходов на душу населения в СФО (229 т/чел. в 2017 г.) более чем в пять раз превысило среднероссийский уровень $(42,4$ т).

Проблема образования и накопления отходов добывающей промышленности рассматривается в работах многих авторов [Боднарук и др., 2013; Озерова, 2015; Ефимов и др., 2017; Хохряков, Цейтлин, 2012]. Все они единодушно поддерживают точку 
зрения о чрезвычайно негативном воздействии на окружающую среду отходов данного вида, несмотря на их принадлежность в основном к IV и V классам опасности ${ }^{4}$.

Под складирование горно-промышленных отходов в целом по России занято свыше 500 тыс. га земель (и плюс к этому ежегодно отчуждается около 10 тыс. га, пригодных для сельского хозяйства $)^{5}$, но их негативное воздействие проявляется на территории, превышающей эту площадь в 10-15 раз.

В процессе разработки месторождений, переработки и обогащения полезных ископаемых на прилегающих к предприятиям территориях накапливаются твёрдые отходы добычи (отвалы, окисленные руды, илы в прудах нейтрализации рудничных вод), хвосты (отходы обогащения полезных ископаемых), отходы металлургической (шлаки, золы и др.) и гидрометаллургической (шламы) переработки. В последнее время к ним применяется термин «техногенные месторождения» и они рассматриваются как дополнительный источник минерального сырья для будущих, а частью - и нынешних разработок. Это гигантские по объемам ресурсы. Например, на Урале (в Республике Башкортостан, Пермском крае, Свердловской и Челябинской областях) к 2016 г. накопилось почти 323 млн т отходов (в том числе 305 млн т V класса опасности), полученных преимущественно при добыче и первичном переделе минерального сырья 6 .

Суммарное содержание полезных компонентов, которые накапливаются в техногенных месторождениях за 20-30 лет, сопоставимо, а иногда и превышает их количество в ежегодно добываемых рудах. Например, на шламохранилище Качканарского ГОК на Среднем Урале по состоянию на 2000 г. насчитывалось более 900 млн т техногенных отходов, содержащих много ценных металлов (скандия, галлия, стронция, титана и др.). При этом количество скандия в них уже в то время превысило 100 тыс. т,

\footnotetext{
${ }^{4}$ Статья 4.1 федерального закона об отходах производства и потребления (введена Ф3 от 30.12.2008 № 309-Ф3): отходы в зависимости от степени негативного воздействия на окружающую среду подразделяются на пять классов опасности: I - чрезвычайно опасные; II - высокоопасные; III - умеренно опасные; IV - малоопасные; V - практически неопасные отходы.

${ }^{5}$ Государственный доклад «О состоянии и об охране окружающей среды Российской Федерации в 2016 году». М.: Минприроды России; НИА-Природа. 2017. 760 с.

${ }^{6}$ Там же.
} 
что составляет более $60 \%$ мировых запасов этого металла [Макаров, 2000].

Помимо отвлечения значительных территорий для складирования, отходы наносят непосредственный вред окружающей природной среде: нарушают естественные биогеохимические циклы, загрязняют вредными и токсичными веществами атмосферу, почву, поверхностные и подземные воды. По экспертным оценкам, на начало 2016 г. было накоплено приблизительно 80 млрд т пород (отходов нефтегазовой, химической, металлургической и горнодобывающей промышленности), содержащих до 16\% токсичных веществ [Проблемы утилизации.., 2015; Умнов, 2017].

Таким образом, цель настоящего исследования - оценка экологической нагрузки отраслей добывающей промышленности - представляется весьма актуальной, а задачи, связанные c ее реализацией (расчет и анализ показателей отходоемкости отраслей, изучение существующих механизмов снижения негативного воздействия на окружающую среду предприятиями добывающей промышленности и разработка основных направлений их совершенствования), чрезвычайно важными и требующими незамедлительного решения.

\section{Методы и материалы}

В исследовании применялись методы межотраслевого анализа. Были рассчитаны прямые коэффициенты образования отходов в сфере деятельности $i\left(g_{\mathrm{j}}\right)$, которые показывают объем образования отходов, полученных при производстве единицы выпуска в отрасли $i$, и могут быть рассчитаны по формуле:

$$
g_{i}=\frac{G_{i}}{X_{i}}
$$

где $G i$ - объем образования отходов в отрасли $i, X_{\mathrm{i}}$ - объем производства в отрасли $i$.

Кроме того, на основе концепции полных затрат межотраслевого баланса были рассчитаны полные коэффициенты образования отходов конкретных отраслей, показывающие количество отходов, полученных при производстве единицы конечного выпуска в отрасли с учетом всех межотраслевых взаимосвязей.

Расчет полных коэффициентов образования отходов может быть получен следующим образом: 


$$
f_{j}=\sum_{i=1}^{n} g_{i} b_{i j},
$$

где $b_{\mathrm{ij}}$-межотраслевые коэффициенты матрицы полных затрат (обратная матрица к матрице, представляющей разность единичной матрицы и матрицы коэффициентов прямых материальных затрат), $n$ - число отраслей.

Полные коэффициенты образования отходов для 2016 г. были получены с использованием последней предоставляемой российской статистикой версии межотраслевого баланса ${ }^{7}$. Прямые и полные коэффициенты образования отходов носят названия прямой и полной отходоемкости, которая показывает истинную удельную нагрузку отраслей на окружающую среду.

Также для оценки последствий институциональных изменений в сфере обращения с отходами были использованы результаты прогнозных расчетов по динамической межотраслевой модели с экологическим блоком, которая была разработана и функционирует в Институте экономики и организации промышленного производства СО РАН. Данный модельный комплекс уже использовался для прогнозирования выбросов загрязняющих атмосферу веществ и сбросов загрязненных сточных вод [Гильмундинов и др., 2011], в последнее время авторами разработана и апробируется методика его использования для оценки объемов загрязнения окружающей среды отходами производства и потребления.

\section{Результаты}

Показатели полной и прямой отходоемкости в добывающих отраслях и в производствах прямого передела их продукции представлены в таблице 1 .

Обращает на себя внимание тот факт, что в некоторых сфеpax экономической деятельности полные коэффициенты многократно превышают прямые: например, при производстве кокса и нефтепродуктов - в 609 раз, производстве и распределении электроэнергии, газа и воды - в 35 раз, в строительстве - в 31 раз.

\footnotetext{
${ }^{7}$ Таблицы ресурсов и использования товаров и услуг за 2015 г. [офиц. сайт Росстата]. URL: http://www.gks.ru/wps/wcm/connect/rosstat_main/rosstat/ru/ statistics/accounts/\# (дата обращения: 01.03.2019).
} 
Таблица 1. Прямая и полная отходоемкость в 2016 г. (в ценах 2015 г.) в отраслях добывающей промышленности и отраслях переработки продукции добывающих отраслей

\begin{tabular}{|c|c|c|c|}
\hline \multirow[t]{2}{*}{$\begin{array}{c}\text { Вид экономической } \\
\text { деятельности }\end{array}$} & \multicolumn{2}{|c|}{$\begin{array}{c}\text { Коэффициенты образования } \\
\text { отходов, кг на } 1 \text { тыс. руб. } \\
\text { валового выпуска }\end{array}$} & \multirow{2}{*}{$\begin{array}{c}\text { Превышение полных } \\
\text { коэффициентов над } \\
\text { прямыми, раз }\end{array}$} \\
\hline & прямые & полные & \\
\hline $\begin{array}{l}\text { Добыча каменного угля, бурого угля } \\
\text { и торфа }\end{array}$ & 3910,7 & 4773,0 & 1,2 \\
\hline Добыча сырой нефти и природного газа & 1,4 & 17,4 & 12,8 \\
\hline Добыча металлических руд & 1883,1 & 1959,6 & 1,0 \\
\hline Добыча прочих полезных ископаемых & 577,4 & 609,9 & 1,1 \\
\hline $\begin{array}{l}\text { Производство кокса и } \\
\text { нефтепродуктов }\end{array}$ & 0,1 & 43,0 & 609,0 \\
\hline Химическое производство & 5,4 & 57,7 & 10,7 \\
\hline $\begin{array}{l}\text { Производство прочих неметаллических } \\
\text { минеральных продуктов }\end{array}$ & 19,3 & 144,2 & 7,5 \\
\hline Металлургическое производство & 38,9 & 435,3 & 11,2 \\
\hline $\begin{array}{l}\text { Производство и распределениеэлектро- } \\
\text { энергии, газа и воды }\end{array}$ & 3,7 & 130,4 & 34,8 \\
\hline Строительство & 2,2 & 68,8 & 31,3 \\
\hline
\end{tabular}

Источник табл. 1, 2: составлено авторами по результатам расчетов.

Поясним процесс образования полных отходов на примере производства кокса. Как видно из таблицы, этот вид деятельности сам по себе не является отходоемким $\left(g_{23}=0,1\right.$ кг на 1 тыс. руб. готовой продукции $\left.{ }^{8}\right)$. Это означает, что при производстве кокса на 1 тыс. руб. (в ценах 2015 г.) образуется лишь 100 г отходов (коксовой крошки). Производство кокса основано на процессе гидролиза, целью которого является отделение углерода от всех остальных веществ, входящих в состав исходного сырья, путем его нагревания без доступа воздуха. Другими словами, кокс получается в результате удаления летучих веществ из каменного угля, поэтому основной негативный эффект от его производства - выбросы загрязняющих атмосферу веществ.

Однако для того, чтобы произвести кокса на 1 тыс. руб., необходимо переработать некоторое количество коксующегося угля

\footnotetext{
${ }^{8}$ Вид деятельности «Производство кокса и нефтепродуктов» занимает 23-ю позицию в Таблице ресурсов и использования товаров и услуг за 2015 г. [офиц. Сайт Росстата] URL: http:/www.gks.ru/wps/wcm/connect/rosstat_main/rosstat/ru/statistics/accounts/\# (дата обращения: 01.03.2019).
} 
(его стоимостной объем оценивается как $a_{10,23}$ тыс. руб., ${ }^{9}$ где $a_{\mathrm{ij}}-$ элемент матрицы коэффициентов прямых материальных затрат). А вот при добыче угля, как уже отмечалось, отходы образуются в большом количестве. Так, при добыче на сумму 1 тыс. руб. будет образовано почти 4 т отходов (вскрышные и вмещающие отходы, отвалы и другие отходы): $g_{10}=3910,7$ кг на 1 тыс. руб.

Таким образом, чтобы произвести кокса на сумму 1 тыс. руб., придется образовать суммарные отходы в количестве не менее $g_{10}$ х $a_{10,23}+g_{23}$ кг (при производстве кокса, кроме угля, используется также продукция других отраслей, тоже образующих отходы). Разделив рассчитанные таким образом полные отходы на объем производства в рассматриваемой отрасли, получим ее полную отходоемкость, которая значительно превышает прямую (для производства кокса и нефтепродуктов - в 609 раз (см. табл. 1)).

По результатам расчетов прямой экологической нагрузки виды деятельности по добыче угля и торфа, металлических руд, прочих неэнергетических полезных ископаемых являются наиболее отходоемкими в экономике, однако их прямая отходоемкость практически совпадает с полной. Если же рассматривать образование отходов с учетом всех межотраслевых связей, к числу наиболее загрязняющих отраслей нужно отнести добычу сырой нефти и природного газа, а также ряд перерабатывающих производств: неметаллических минеральных продуктов, кокса и нефтепродуктов, металлургию и производство готовых металлических изделий, производство и распределение электроэнергии, газа и воды. На наш взгляд, для этих видов экономической деятельности удельную нагрузку на окружающую среду в сфере образования отходов необходимо оценивать по полной отходоемкости.

Анализ динамических процессов показывает, что коэффициенты как прямой, так и полной отходоемкости существенно не менялись с начала 2000-х гг., что говорит об отсутствии значительных технологических изменений в рассматриваемых отраслях. Таким образом, некоторое сокращение среднегодовых темпов прироста накопленных отходов (табл. 2) объясняется

\footnotetext{
${ }^{9}$ Вид деятельности «Производство каменного и бурого угля» занимает 10 -ю позицию в Таблице ресурсов и использования товаров и услуг...
} 
экономическими трудностями конъюнктурного характера, периодически возникающими в годы кризисов и рецессии.

\section{Таблица 2. Среднегодовые темпы роста накопленных отходов по видам экономической деятельности в 2006-2017 rr. , \%}

\begin{tabular}{|l|c|c|c|}
\hline \multicolumn{1}{|c|}{ Вид экономической деятельности } & 2006-2009 & 2010-2013 & 2014-2017 \\
\hline Добыча каменного угля, бурого угля и торфа & 109 & 111 & 108 \\
\hline Добыча металлических руд & 111 & 109 & 106 \\
\hline $\begin{array}{l}\text { Добыча прочих неэнергетических полезных } \\
\text { ископаемых }\end{array}$ & 111 & 109 & 107 \\
\hline Химическое производство & 113 & 107 & 103 \\
\hline Металлургия & 112 & 108 & 106 \\
\hline $\begin{array}{l}\text { Производство и распределениеэлектроэнергии, } \\
\text { газа и воды }\end{array}$ & 114 & 107 & 103 \\
\hline
\end{tabular}

\section{Обсуждение}

В последние годы в связи с реформированием сферы обращения с отходами, в обществе и в органах государственного управления повысился интерес к проблеме переработки отходов. В начале 2018 г. Правительством РФ была принята Стратегия развития промышленности по обработке, утилизации и обезвреживанию отходов производства и потребления на период до 2030 г. (далее - Стратегия), согласно которой предполагается довести долю утилизированных и обезвреженных отходов в общем объеме образованных отходов до уровня развитых стран (86\%). В этих целях по всей стране предполагается создание 70 экотехнопарков и 226 производственно-технических комплексов по обработке, утилизации и обезвреживанию отходов.

В настоящее время функционирует только шесть таких комплексов. Строительство экотехнопарков активно начато в 2019 г. Раньше всех (по оценкам специалистов, в 2022 г.) будет введен в действие экотехнопарк в Новокузнецке, который создается на базе существующего технопарка «Западный». Согласно Инновационному сценарию Стратегии, к 2030 г. уровень образования отходов по сравнению с 2016 г. должен снизиться на 3,7\%. На наш взгляд, эти цифры выглядят не слишком реалистично, потому что в настоящее время уровень образования отходов растет: в 2016 г. на 6\% относительно предыдущего года, в 2017 г. - на 15\%. 
Немало внимания в документе уделено проблемам снижения экологической нагрузки добывающих отраслей, однако развитие новых способов утилизации отходов добывающей промышленности Стратегия связывает главным образом с усовершенствованием технологий закладки горных выработок, основывающихся на создании и применении специальных пластичных материалов. При этом, к сожалению, в ней ничего не говорится о внедрении современных технологий утилизации и переработки уже имеющихся и продолжающих накапливаться техногенных отходов, хотя уже имеется опыт эффективного их использования [Ладыгин и др., 2018; Кнатько и др., 2015; Абдрахимов, Колпаков, 2019].

Например, в Красноярском крае на объектах ООО «Славнефть-Красноярскнефтегаз» переработка отходов производится непосредственно на нефтяном месторождении без складирования шламов в специализированных амбарах и на полигонах. На Куюмбинском месторождении для этого используется установка термической деструкции (УТД-2-800 и УТД-2-2000) производства компании IPEC (ПГ «Безопасные Технологии») [Ладыгин и др., 2018].

Принцип ее работы основан на низкотемпературном пиролизе: нагревании нефтесодержащих отходов в условиях дефицита кислорода с последующим разделением, конденсацией и очисткой полученного продукта. На выходе получаются техническая вода, которая подходит для приготовления новых партий буровых растворов, и промышленный грунт, используемый для отсыпки автодорог, обваловки площадок и скважин, рекультивации карьеров. Эта технология хорошо подходит для переработки кислых гудронов, которые образуются при контакте нефти и нефтепродуктов с серной кислотой, используемой при нефтепереработке, а также в химической промышленности - при переработке резины и старых шин, некоторых видов пластика, пленок и замазученных грунтов.

Производительность описываемой установки - 2000 кг нефтесодержащих отходов в час, ее использование непосредственно на участке добычи позволяет предприятию значительно сократить расходы на переработку, вывоз и захоронение отходов, а также снижает негативное воздействие на окружающую среду.

На сегодня подобные установки применяются на Вангапуровском месторождении (ПАО «Газпром», г. Ноябрьск), на Щельяюрском (ПАО «Лукойл», Республика Коми), пользуются спросом 
у зарубежных компаний. На наш взгляд, в России необходимо стимулировать более широкое применение данной технологии. В том числе потому, что основной способ снижения экологической нагрузки при нефтедобыче, используемый в настоящее время - это разведение отходов водой для снижения класса опасности c V до IV. Это самый «дешевый» и простой на сегодня метод. Однако с экологической точки зрения он весьма сомнителен, поскольку приводит к непозволительным тратам водных ресурсов.

Возвращаясь к вопросу о реалистичности Инновационного сценария Стратегии, отметим, что, по нашей прогнозной оценке, для отраслей добывающей промышленности, даже если реализовать все намеченные планы (а практика показывает, что это редко получается), удастся лишь снизить темпы прироста накопленных отходов в 2,7 раза (с 7,1\% в 2017 г. до 2,6\% в 2024 г.), но никак не сократить их объем.

Для более активной борьбы с накопленными отходами, с точки зрения авторов, необходимо вводить новые институциональные механизмы, которые бы позволили стимулировать, прежде всего, ввод в действие новых мощностей по переработке отходов на основе современных технологий. В условиях слабого инвестиционного климата и общих проблем развития добывающих отраслей задача представляется достаточно сложной [Алексеев, Кузнецова, 2011; Kontorovich et al., 2018].

\section{Заключение}

Итак, отрасли добывающей промышленности и смежные с ними перерабатывающие производства являются основным источником формирования производственных отходов в России. Однако существующая система учета экологической нагрузки далеко не всегда позволяет адекватно оценить тот вред, который то или иное производство наносит окружающей среде. Истинную удельную нагрузку на окружающую среду необходимо оценивать с помощью показателей полной отходоемкости, рассчитанной с учетом всех межотраслевых взаимосвязей. Особенно это касается таких видов деятельности, как металлургия и производство готовых металлических изделий, производство и распределение электроэнергии, газа и воды, добыча сырой нефти и природного 
газа, производство неметаллических минеральных продуктов, кокса и нефтепродуктов.

К сожалению, во властных кругах, в статистических органах господствует точка зрения об относительно низкой вредоносности отходов добывающей промышленности, поскольку они относятся в основном к V классу опасности. Очевидно, именно этим обусловлено отсутствие в современном законодательстве, включая стратегические документы, эффективных стимулов для повышения степени переработки и использования отходов этих отраслей.

Деятельность по обращению с отходами V класса практически не лицензируется. Экологические сборы за тонну таких отходов в 2019 г. составляют всего 1,14 руб. ${ }^{10}$ Часто предприятия стремятся перевести отходы I-IV класса опасности в V класс или сертифицируют их в качестве сырья, что позволяет экономить на плате за негативное воздействие на окружающую среду (НВОС).

Более того, на сегодняшний день предприятиям на законных основаниях разрешается в течение 11 месяцев накапливать отходы на своей территории с целью их дальнейшей утилизации и обезвреживания (снижения массы, обеззараживания и т.д.) - без уплаты платежей НВОС. Однако фактически в течение всего этого времени (а зачастую гораздо дольше, как показывает практика) происходит беспрепятственное выделение вредных веществ в атмосферу, проникновение в почву и грунтовые воды, то есть природе наносится ущерб, за который никто не несет ответственности. Между тем безопасное размещение отходов (за которое и взимаются сборы НВОС) подразумевает их хранение и захоронение в специально предназначенных для этого объектах.

C точки зрения авторов, в Стратегии развития промышленности по обработке, утилизации и обезвреживанию отходов производства и потребления на период до 2030 г. недостаточно внимания уделяется механизмам решения экологических проблем отраслей добывающей промышленности. По нашей оценке, реализация Инновационного сценария Стратегии позволит

\footnotetext{
${ }^{10}$ Постановление Правительства РФ от 13.09.2016 № 913 «О ставках платы за негативное воздействие на окружающую среду и дополнительных коэффициентах» // Консультант Плюс. URL: http://www.consultant.ru/cons/cgi/online.cgi?req=doc\&base=LAW $\& n=301545 \& \mathrm{fld}=134 \& \mathrm{dst}=1000000001,0 \& \mathrm{rnd}=0.6211451662364209 \# 008461947688806148$ (дата обращения: 14.04.2019).
} 
лишь снизить темпы прироста накопленных отходов в 2,7 раза, но не сократить их объем.

Эти и другие пробелы в экологическом законодательстве и в программных документах природоохранного характера необходимо ликвидировать в ближайшей перспективе, чтобы добиться существенного сокращения накопления отходов производства и потребления.

\section{Литература}

Абдрахимов В. З., Колпаков А.В. Аспекты использования отходов топливно-энергетического комплекса и химической промышленности в производстве керамического кирпича // Экология и промышленность России. 2019. Т. 23. № 1. C. 11-14.

Алексеев А.В., Кузнецова Н.Н. Инвестиционный процесс в российской экономике в условиях неустойчивого экономического роста // Инвестиции в России. 2011. № 3. С. 3-11.

Боднарук М.Н., Савон Д.Ю., Маркер Е.В., Проскурникова И.А., Адигамова Ж.А., Аржаткина М.С., Ларионова Е.Н., Полихронова О.Т. Эколого-экономические проблемы топливно-энергетического комплекса России: Горный информационно-аналитический бюллетень (научно-технический журнал). Отдельные статьи (специальный выпуск). М.: Горная книга. 2013. № 9.38 с.

Гильмундинов В.М., Казанцева Л. К., Тагаева Т. О. Проблемы охраны водных и атмосферных ресурсов России / Отв. ред. А. Г. Коржубаев, Новосибирск. ИЭОПП СО РАН, 2011. $166 \mathrm{c}$.

Ефимов В.И., Сиборов Р. В., Корчагина Т.В. К вопросу образования отходов производства от предприятий угольной отрасли в Кузбассе // Горный информационно-аналитический бюллетень. 2017. № 1. С. 85-96.

Кнатько М., Жабриков С., Подлипский И. Утилизации отходов топливноэнергетического комплекса // Экология и промышленность России. 2015. Т. 19. № 4. C. 20-23.

Ладысин К.В., Стомпель С.И., Спектор Ю.Л. Утилизация нефтесодержащих отходов // Экология производства. 2018. № 4. С. 70-73.

Макаров А.Б. Техногенные месторождения минерального сырья // Cоросовский образовательный журнал. 2000 г. Т. 6. № 8. С. 76-80.

Озерова Е.M. Обоснования территориальных схем обращения с отходами для организаций нефтедобывающей и нефтеперерабатывающей промышленности // Сфера. Нефть и газ. 2015. № 2. С. 106-108.

Проблемы утилизации отходов на предприятиях топливно-энергетического комплекса // Центр сертификации и лицензирования «Единый стандарт». 27.05.2015. URL: https://1cert.ru/stati/problemy-utilizatsii-otkhodov-napredpriyatiyakh-tek (дата обращения: 11.04.2019).

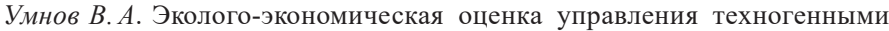
месторождениями // Вестник РГГУ. 2017. № 2 (8). С. 21-29.

Хохряков А.В., Цейтлин Е.М. Образование отходов металлургических предприятий Урала и их воздействие на окружающую среду // Известия Самарского научного центра Российской академии наук. 2012. Т. 14. № 1 (3). С. 834-837. 
Kontorovich A.E., Eder L.V., Filimonova I.V., Nikitenko S.M. Key problems in the development of the Power of Siberia project // Regional Research of Russia. 2018. Vol. 8. № 1. P. 92-100.

Статья поступила 17.05.2019.

Для цитирования: Тагаева Т. О., Гильмундинов В. М., Казанцева Л. К. Проблема накопления отходов в отраслях добывающей промышленности РФ// ЭКО. 2019. № 9. C. 117-131. DOI: 10.30680/ECO0131-7652-2019-9-117-131.

\section{Summary}

Tagaeva, T. O. Doct. Sci. (Econ.), Institute of Economics and Industrial Engineering, SB RAS, Novosibirsk State University

Gilmundinov, V.M., Cand. Sci. (Econ.), Institiute of Economics and Industrial Engineering, SB RAS, Novosibirsk State University

Kazantseva, L.K., Cand. Sci. (His.), Institute of Economics and Industrial Engineering, SB RAS, Novosibirsk

\section{Federation \\ The Problem of Accumulating Industrial Mining Waste in the Russian}

Abstarct. The article deals with problems of generation and accumulation of waste in mining industries and industries engaged in processing of its products. These areas of activity are the main source of waste generation in Russia. The authors calculated direct and total coefficients of waste generation in the mining industries that allow assessing the load on the environment. The Strategy for development of waste treatment industry up to 2030 is analyzed. The article discusses the main directions of improving institutional mechanisms of the Russian environmental legislation, which are necessary for successful implementation of the Strategy's goals and objectives.

Keywords: generation and accumulation of industrial waste; man-made deposits; direct and total coefficients of waste generation; Strategy for development of waste treatment industry

\section{References}

Abdrakhimov, V.Z., Kolpakov, A.V. (2019). Aspects of the use of waste fuel and energy complex and chemical industry in the production of ceramic bricks. Ecology and Industry of Russia. Ekologiya i promyshlennost' Rossii. Vol. 23. No. 1. Pp. 11-14. (In Russ.).

Alekseev, A.V., Kuznetsova, N.N. (2011). Investment process in the Russian economy in the conditions of unstable economic growth. Investments in Russia. Investitsii v Rossii. No. 3. Pp. 483-491. (In Russ.).

Bodnaruk, M.N., Savon, D. Yu., Marker, E.V., Proskurnikova, I.A., Adigamova, J.A., Arzhatkina, M.S., Larionova, E.N., Polikhronova, O.T. (2013). Ecological and economic problems of the fuel and energy complex of Russia: Mining information and analytical bulletin (scientific and technical journal). Selected articles (special issue). Gornyy informatsionno-analiticheskiy byulleten' (nauchnotekhnicheskiy zhurnal). Otdel'nyye stat'i (spetsial'nyy vypusk). Moscow. Mining Book Publishing House. No. 9. 38 p. (In Russ.). 
Efimov, V.I., Siborov, R.V., Korchagina, T.V. (2017). On the issue of production waste from the coal industry enterprises in Kuzbass. Mining information and analytical bulletin. Gornyy informatsionno-analiticheskiy byulleten'. No.1. Pp. 85-96. (In Russ.).

Gilmundinov, V.M., Kazantseva, L.K., Tagaeva, T.O. (2011). Problems of water and atmospheric resources protection in Russia / resp. edited by A. G. Korzhubaev; IEIE SB RAS. Novosibirsk. 166 p. (In Russ.).

Khokhryakov, A.V., Zeitlin, E.M. (2012). Formation of wastes of metallurgical enterprises of the Urals and their impact on the environment. Proceedings of the Samara Scientific Center of the Russian Academy of Sciences. Izvestiya Samarskogo nauchnogo tsentra Rossiyskoy akademii nauk. Vol. 14. No. 1 (3). Pp. 834-837. (In Russ.).

Knat'ko, M., Zhabrikov, S., Podlipsky, I. (2015). Utilization of the Waste of the Fuel-Energy Complex. Ecology and Industry of Russia. Ekologiya i promyshlennost' Rossi. T. 19. No. 4. Pp. 20-23. (In Russ.).

Kontorovich, A.E., Eder, L.V., Filimonova, I.V., Nikitenko, S.M. (2018). Key problems in the development of the Power of Siberia project. Regional Research of Russia. Regional Research of Russia. Vol. 8. No. 1. Pp. 92-100.

Ladygin, K.V., Stompel, S.I., Spektor, Yu.L. (2018). Disposal of oily waste. Ecology of production.Ekologiya proizvodstva. No. 4. Pp. 70-73. (In Russ.).

Makarov, A.B. (2000). Technogenic deposits of mineral raw materials. Soros Educational Journal. Sorosovskiy obrazovatel'nyy zhurnal. No. 8(6). Pp. 76-80. (In Russ.).

Ozerova, E.M. (2015). Justification of territorial waste management schemes for organizations of the oil producing and refining industry. Sphere. Oil and gas. Sfera. Neft'i gaz. No. 2. Pp. 106-108. (In Russ.).

Problems of waste disposal at the enterprises of the fuel and energy complex (2015). Certification and licensing center "Unified Standard" 27.05.2015. Tsentr sertifikatsii $i$ litsenzirovaniya "Yedinyy standart». 27.05.2015. Available at: https://1cert.ru/stati/problemy-utilizatsii-otkhodov-na-predpriyatiyakh-tek (accessed 11.04.2019). (In Russ.).

Umnov, V.A. (2017). Ecological and economic assessment of the management of technogenic deposits. Bulletin of the RSUH. Vestnik RGGU. No. 2 (8). Pp. 21-29. (In Russ.).

For citation: Tagaeva, T.O., Gilmundinov, V.M., Kazantseva, L.K. (2019). The Problem of Accumulating Industrial Mining Waste in the Russian Federation. ECO. No. 9. Pp. 117-131. (In Russ.). DOI: 10.30680/ECO0131-7652-2019-9-117-131. 